\title{
Encouraging Offline Banking Customers to Adopt Online Banking: A Study on Customers of Dhaka City
}

\author{
Dr. Rezwanul Huque Khan ${ }^{1 *} \quad$ Anika Shahjabin ${ }^{2}$ \\ 1.Associate Professor, IBA, University of Dhaka, Dhaka-1000, Bangladesh \\ 2.Anika Shahjabin, Manager, Mayalogy Ltd., Dhaka, Bangladesh
}

\begin{abstract}
While the use of technologies in banking services is on the rise worldwide, a substantial percentage of customers, specially in developing countries, still prefer the traditional forms of banking. This study aims to investigate the factors that inhibit customers of offline banking to switch towards online banking. In addition, it also identifies the factors that influence those customers positively towards online banking. Data were collected from 236 customers who conduct transactions traditionally in different banks in Dhaka city and who do not take any online services from any bank. The data collected from the survey were analyzed using the IBM SPSS package. Both descriptive and inferential statistical tools were used for analysis. Our study shows that customers of offline banking have lack of trust/confidence in online banking services and consider the services are associated with risk, which inhibits them to switch to online banking. On the other hand, customers of offline banking are found to perceive that online banking services are useful and facilitating conditions are favorable for taking online services. However, the customers are found to be in a confusing state about the ease of use of the services. Interestingly, about $71 \%$ of the traditional customers are found to switch to online banking mode if their concerns with the later system are addressed. Finally, based on these findings, implications for banking practitioners and policy makers are articulated.
\end{abstract}

Keywords: Offline banking, switching, adoption, online banking, Dhaka

DOI: $10.7176 / \mathrm{EJBM} / 13-3-06$

Publication date: January $31^{\text {st }} 2021$

\section{Introduction}

Over the last two decades, service firms across the world have made considerable investments in technology to gain a competitive advantage in the market. In fact, by harnessing technologies, those firms have transformed the ways they used to operate their business. Specially, customer-side operations have been radically changed and have gained center-stage in many of those firms (Setia et al., 2013). In line with that, banks have ventured into newer avenues by introducing different technologies to cater to their existing customers better and attract new customers. Since technologies offered by banks facilitate customers with extending business hours, improved design, interface and functionality along with superior service quality, banks using technologies have gained popularity resulting in the proliferation of different technology-enabled services (Curran and Meuter, 2007).

Though the use of technologies is on the rise worldwide, a substantial percentage of customers of financial institutions still prefer the traditional forms of banking. According to Global Findex Database (2017), among the account owners in high-income economies, only $55 \%$ customers (which is $51 \%$ of adults) made at least one financial transaction in 2016 using internet or mobile phone, while in developing economies only $30 \%$ of the account owners (which is $19 \%$ of adults) used mobile phone or internet at least once for financial transaction in that year. It reflects that despite the numerous advantages offered by technologies, a significant percentage of account owners (around 70\%) in developing economies do not prefer different technologies deployed in banks. Rather, they are still seen queuing up in lines in front of banks even for services they could have availed easily using online banking. Hence, banks in the emerging economies have huge opportunities to bring those traditional customers into the digital platforms to experience better service (Global Findex Database, 2017).

Online banking, by definition, means managing one's bank account with a computer or mobile device being connected through the internet (Murakami-Fester, 2020). This may include transferring funds, checking account details, depositing checks and paying bills electronically. Online banking allows customers to produce and consume banking services without interference from employees (Meuter, 2007). It could help banks to further their goal of financial inclusion and win a major section of customers. However, introducing merely technologies to the existing or new customers would not fetch anticipated changes in the scenario (Curran and Meuter, 2007). Rather, it is really challenging to induce new customers or to alter the behavioral intention of existing customers to adopt online banking from the traditional form of banking. Hence, a challenge for the banks is to understand the technological and other features that will enable them to attract or deter customers from adopting it and how those online banking could be presented as an attractive alternative channel for the existing customers. Given the backdrop, in this study, we aim to investigate how the adoption of online banking could be encouraged to customers who prefer the traditional form of banking. The research questions we try to address is- which features of online banking inhibit existing traditional customers to adopt online banking? 
We seek answers of this question by investing the customers who use the only traditional forms of banking and have not used online banking. We try to explore the factors which hinder the customers to adopt online banking and accordingly offer recommendations for bringing them into the bandwagon.

The rest of the paper is structured as follows. Following a review of the relevant literature, we explain the methodology we have adopted in this study. This is followed by the analysis and findings, and the discussion section. Finally, the paper ends with a concluding remark.

\section{Literature Review}

\subsection{Online banking}

Online banking has been defined as the process of managing one's bank account with a computer or mobile device being connected through the internet (Murakami-Fester, 2020). To provide better customer experience and to enhance productivity and proficiency in the operational process, banks have introduced online banking as a channel besides their traditional process (Kelly et al., 2017; McGrath \& Astell, 2017). In doing so, many banks have been able to better address the customer's demand leading to satisfied and loyal customers (Ganguli \& Roy, 2011). In addition, banks have been able to serve more customers with fewer resources resulting in cost reduction (Iqbal et al., 2018; Yang \& Klassen, 2008). These led banks to invest in technologies or online banking. Along with conducting different banking services through the internet, while online banking includes using ATMs and transferring money through apps in mobile (which does not need to have a bank account), for the simplicity of the study and to focus on a specific issue, this study excludes the later ones.

The Global Findex Database (2017) showed that in high-income economies, only 55\% customers (which is $51 \%$ of adults) made at least one financial transaction in 2016 using internet or mobile phone, while in developing economies only $30 \%$ of the account owners (which is $19 \%$ of adults) did the same. The study shows that one of the barriers to the adoption of online banking is the lack of access to mobile phones and the internet. Indeed, extant literature discusses a lot of barriers and challenges in adopting technologies in developing countries. On the other hand, many of the studies focus on the factors that influence the adoption of technologies in developing countries which we discuss in the following section.

\subsection{Factors influencing customers' perception about online banking}

Extant literature shows different factors that influence the adoption of online banking. In a study on online banking customers of India conducted by Jitendra and Sharma (2017), it was found that transactional privacy and trust play a vital role in adopting online banking. Other factors identified in this study that motivates customers to opt for online banking are perceived usefulness and perceived ease of use, convenience and perceived control. The study found that within the same group of individuals perception for adopting online banking had varied attitudinal differences.

In another study, Estrella et al. (2016) analyzed panel data of 1357 customers collected by a large Spanish Bank to discover the impact of customers' offline transaction behavior in terms of loyalty and adoption of selfservice technologies (SST) in online banking. This study is particularly relevant to our study for its integration of the pre-adaptation stage of online banking. The study showed that customers with lower levels of purchase recency and cancellation recency are more prone to switch to online banking (2016). The underlying assumption of this finding was that anonymity, convenience, accessibility and improved service efficiency offered by internet channels influence them to adopt SSTs. However, the perceived utility of a product consists of more factors like convenience, choice, availability of sociality, fashion, value, and authority (Yi-Chun, 2010). With the advent of new services and technology, expectations evolve around many more complex factors than before such asproactive service, personalized interactions and connected experiences across channels (Salesforce Research, 2020). The results from the study conducted by Estrella et al. (2016) showed that monetary value and level of high-risk product ownership have very less impact on SST adoption. This proves that, since high-risk can cast doubt and uncertainty on customers' end, they perceive online banking as an insecure mode of interaction with the bank.

Youssef et al. (2017) investigated the association between behavioral intentions such as perceived usefulness, perceived ease of use, web security and attitude, by conducting a survey among 700 respondents. The results showed that $63 \%$ of the behavioral intent accounted for by customers' attitudes. The variation of attitude was found to be greatly influenced by perceived usefulness followed by web security. The results indicated that perceived usefulness directly impacts both behavioral intention and attitude using online banking and, failure to cater to this factor might negatively impact technology adaptation and loyalty.

Almsalam (2014) analysed the relationship between two factors of customer satisfaction, namely customer expectation and perceived service quality. According to Almsalam, sources like- prior exposure to service, word of mouth, expert opinion, publicity and communication lead to expectation about future service encounters and, these expectations highly influence consumer decision making. The study was conducted on 250 customers of 5 banks and revealed that customer expectation and perceived service quality have a positive effect on customer 
satisfaction.

Trust and confidence in a service provider is another factor that can impact customer perception and satisfaction about banking services (Mamun \& Khan, 2014). In the traditional banking environment, there is direct physical contact between bankers and consumers. As a result, consumers can use physical cues, such as observing the sales people or the physical office or store space in order to judge trustworthiness (Reichheld \& Schefter, 2000). On the other hand, in an online environment, consumers cannot experience the service physically. Customers and banks face spatial and temporal separation (Grabner-Kraeuter, 2002). There is also a fear of hacking and privacy invasion (Hoffman, Novak, \& Peralta, 1999; Yoon, 2002). Consequently, the prevailing reluctance to switch transaction modes means that banks need to address intentions to change behaviour plans to promote online banking to their customers.

Again, social acceptance has been found to play a profound role in technology adaptation for banking services. An important area to look into while determining factors that influence technology adaptation is the external impressions that people are subject to (Pietro, 2012). These external impressions come in the form of social influence and subjective norms. In terms of using online banking, there is enough evidence that recommendations from family and friends were an important factor in consumer adoption of an SST (Barry Howcroft, 2002). Subjective norms are a combination of two concepts- external influence and interpersonal influence. External influence comes from newspaper, media and other marketing strategies adopted by companies. Interpersonal influence refers to word-of-mouth influence by reference groups like- friends, superiors and experts (Pietro, 2012).

As such, based on the literature review, we identified perceived risk, perceived usefulness, perceived use of use, trust/confidence in service providers and other facilitating conditions represented by societal factors, as the major determinants of customers' behavioural intention towards online banking. Taking those factors into consideration, in this study, we intend to focus on customers using traditional banking to explore what factors inhibit them to adopt online channels in banks.

\section{Methodology}

To fulfill the objective of our study, we conducted a quantitative study. Data were collected from both primary and secondary sources. The secondary data was collected from various journals, books, research reports, articles and government publications. We also went through different online portals to collect information about consumers' perceptions regarding the banking industry as a whole. Primary data was collected through a questionnaire survey. The first section of the questionnaire focused on participants' demographic profiles while the second part contained factors that affected consumer perception about online banking services. Likert scales have been used in the questionnaire and respondents were asked to indicate their opinions by checking how strongly they agree or disagree with the statements provided in this section. Respondents were asked to pick any one of the five alternatives- strongly agree, agree, indifferent, disagree and strongly disagree where 1 indicated strongly agree and 5 indicated strongly disagree respectively. Since the sample size of all the users of traditional banking services in Dhaka city was pretty large and beyond our reach, we have used a combination of nonprobabilistic convenience and judgmental sampling for conducting the survey. Using the following formula, we calculated our sample size: where, $\mathrm{n}=$ Sample size, $\mathrm{z}=$ cut-off value for desired confidence level (at 95\%, where $\mathrm{z}$ value was taken from normal distribution table), $\mathrm{p}=$ proportion of educated people who smoke, $\mathrm{q}=$ proportion of educated people who do not smoke (1-p) and $\mathrm{d} 0=$ Precision. We desired a precision level of $6.67 \%$ if to keep the confidence interval at $95 \%$. The value of $\mathrm{p}$ and $\mathrm{q}$ will be taken as 0.5 because we want equal representation of the population. The sample size of the survey calculated was: $n=\frac{(1.96)^{2} *(0.5) *(0.5)}{\left(d_{0}\right)^{2}}$

$=216$. For our primary source of data, we approached to 291 customers with the questionnaire who were conducting transactions being physically present in different banks in Dhaka city. But, finally, the questionnaire was filled up from 236 customers who did not take any online services from any bank. The data collected from the survey were analyzed using the IBM SPSS package. Both descriptive and inferential statistical tools were used for analysis. Descriptive Statistics were calculated for the different variables and used to identify the factors inhibiting customers of traditional banking to adopt the online system of banking. 


\section{Analysis and Findings}

\subsection{Respondents' profile}

Table 1: Respondent Profile

\begin{tabular}{|c|c|c|}
\hline & Factor Considered & Percentage \\
\hline \multirow[t]{3}{*}{ Gender } & & \\
\hline & Male & 75.85 \\
\hline & Female & 24.15 \\
\hline \multirow{8}{*}{ Age } & $18-22$ years & 9.28 \\
\hline & $23-27$ years & 16.03 \\
\hline & $28-32$ years & 11.40 \\
\hline & $33-37$ years & 18.57 \\
\hline & $38-42$ years & 17.72 \\
\hline & Over 43 years & 27.00 \\
\hline & Secondary or less & 13.97 \\
\hline & Higher Secondary & 23.71 \\
\hline \multirow[t]{3}{*}{ Education } & Graduation & 29.78 \\
\hline & Post-Graduation & 20.30 \\
\hline & No Formal Education & 12.24 \\
\hline \multirow{6}{*}{ Occupation } & Student & 18.14 \\
\hline & Private Service holder & 9.28 \\
\hline & Public Service holder & 17.72 \\
\hline & Business/Entrepreneur & 36.29 \\
\hline & Homemaker & 13.08 \\
\hline & Others & 5.49 \\
\hline \multirow{6}{*}{ Income level } & Below BDT 15000 & 24.05 \\
\hline & BDT $15001-30000$ & 18.57 \\
\hline & BDT $30001-45000$ & 26.16 \\
\hline & BDT $45001-60000$ & 10.13 \\
\hline & BDT $60001-75000$ & 9.70 \\
\hline & Over BDT 75001 & \\
\hline
\end{tabular}

Our analysis shows that among the respondents in the survey, around $76 \%$ were male while only $24 \%$ were female. More than $75 \%$ of the respondents were of aged above 28 years within which $27 \%$ were over 43 years. Again, almost $50 \%$ of the respondents were found to have educational qualifications up to higher secondary degree while $50 \%$ of the respondents completed graduation or post-graduation. In terms of occupations, about $36 \%$ of respondents are involved in business or entrepreneurship, followed by $18 \%$ of students and $27 \%$ are service holders. Our analysis shows that $26.16 \%$ of the respondents have a monthly salary between BDT 30000 to 45000 following $24.05 \%$ of the respondents having a monthly salary below BDT 15,000 while around $11 \%$ earn more BDT 75,000. Details of the respondents are given in the following table (Table 1).

\subsection{Perception of users of offline banking regarding online banking}

Our analysis finds out the perception of the customers of traditional banking regarding online banking services. This section discusses the findings about different factors.

\subsubsection{Perceived risk}

Our analysis shows that respondents perceive online banking somewhat risky. Under the complex variable "Perceived Risk", five single variables were considered. Among these single variables, "Mistake done may be difficult to correct" has the lowest mean score of 3.32. It means that respondents are not sure of the fact that if they make any mistake during an online transaction, it would be easy or difficult to correct those mistakes. They also have a perception (3.96) that the confidential information they would be sharing with banks for online banking might be shared with others or be used for other purposes. In addition, to some extent, they have a fear of losing money if transactions are done online. Similarly, they perceive that there is a threat of hacking or a threat of others' capability to access their' bank account in online banking. As a whole, they perceive online banking is somewhat risky (3.596) and that can be argued as one of the reasons for which they do not use online banking. 
Table 2: Perception regarding risk

\begin{tabular}{|c|l|c|}
\hline Complex Variable & \multicolumn{1}{|c|}{ Simple Variables } & Mean Value \\
\hline \multirow{4}{*}{$\begin{array}{c}\text { Perceived Risk } \\
\text { (3.596) }\end{array}$} & Privacy will not be compromised & 3.96 \\
\cline { 2 - 3 } & Personal Information will not be hacked & 3.65 \\
\cline { 2 - 3 } & Mistakes done will be easy to correct & 3.32 \\
\cline { 2 - 3 } & There is no fear of losing money & 3.52 \\
\cline { 2 - 3 } & Others would not be able to access account & 3.53 \\
\hline
\end{tabular}

4.2.2 Perceived usefulness

Our analysis shows that the respondents are quite confident about the usefulness of online banking as denoted by the mean score of 1.77. Table 3 shows the details of customers' perceived usefulness regarding online banking. It shows that the complex variable "Perceived Usefulness" consists of four simple variables and the respondents agree with all the variables, that is, they perceive online banking saves time, is convenient, cheaper and easily accessible. As such, the customers of offline banking have a positive perception regarding the usefulness of online banking and it cannot inhibit them to adopt online banking rather may work as a motivator.

Table 3: Perception regarding usefulness

\begin{tabular}{|c|l|c|}
\hline Complex Variable & \multicolumn{1}{|c|}{ Simple Variables } & Mean Value \\
\hline \multirow{4}{*}{$\begin{array}{c}\text { Perceived usefulness } \\
(1.77)\end{array}$} & May save time & 1.44 \\
\cline { 2 - 3 } & May be more convenient than coming here & 1.62 \\
\cline { 2 - 3 } & May be cheaper & 2.07 \\
\cline { 2 - 3 } & May be easily accessible from anywhere & 1.96 \\
\hline
\end{tabular}

\subsubsection{Perceived ease of use}

In this study, five simple variables were considered under the complex variable "Perceived Ease of Use". Among these simple variables, all the variables except "need training to use" got a mean score above 3 . They have a neutral perception about the fact that they need training (2.83) while using online banking services and the whole online process is user friendly (3.12). However, they disagree that if they face technical issues availing online banking services, banks can address the issues easily and the adopted technology may be easy to use. Overall, the respondents have a neutral perception (3.358) about the perceived ease of use of online banking which means that respondents are not sure that the technology adopted by banking institutions and offered through online services are easy to use. As such, ease of use neither motivates nor inhibits the users to switch to online banking from traditional banking.

Table 4: Perception of ease of use

\begin{tabular}{|c|l|c|}
\hline Complex Variable & \multicolumn{1}{|c|}{ Simple Variables } & Mean Value \\
\hline \multirow{4}{*}{$\begin{array}{c}\text { Perceived Ease of Use } \\
(3.358)\end{array}$} & Technology adopted is easy to use & 3.53 \\
\cline { 2 - 3 } & Need help during use & 3.45 \\
\cline { 2 - 3 } & Need training to use & 2.83 \\
\cline { 2 - 3 } & Any technical issue arises can be easily addressed by me & 3.86 \\
\cline { 2 - 3 } & The whole process of using it is user friendly & 3.12 \\
\hline
\end{tabular}

\subsubsection{Perceived trust/confidence}

Our analysis in Table 5 shows that the respondents have lack of trust or confidence $(3.974 \sim 4)$ on the online banking service providers which results into their reservation to switch from traditional banking services. The Table shows the overall mean score of "Trust/confidence" and also the seven simple variables considered under this complex variable. The respondents strongly disagree that any technical issue which may arise during a transaction will be addressed instantly as the mean score is 4.91 . Our analysis also shows that the offline banking customers have almost a similar negative perception that any account-related problem will not be settled promptly, their interest will not be bank's first priority and their mistakes will not be taken care of empathetically. However, they somewhat agreed that through online banking services mistakes by banks will be handled with the utmost integrity and that banks would put effort to protect fraudulent activities. The analysis also shows that the customers are somewhat unsure (mean score 3.40) whether the bank will notify them of any issue that has a relationship with their account instantly or not. 
Table 5: Perceived trust/confidence in online banking

\begin{tabular}{|c|l|c|}
\hline Complex Variable & \multicolumn{1}{|c|}{ Simple Variables } & Mean Value \\
\hline \multirow{4}{*}{$\begin{array}{c}\text { Perceived } \\
\text { Trust/Confidence } \\
\mathbf{( 3 . 9 7 4 )}\end{array}$} & Mistakes by banks will be handled with utmost integrity & 2.98 \\
\cline { 2 - 3 } & Banks put enough effort to protect fraudulent activities & 2.90 \\
\cline { 2 - 3 } & Any complaint will be settled promptly & 4.67 \\
\cline { 2 - 3 } & Any technical issue arises will be addressed instantly & 4.91 \\
\cline { 2 - 3 } & My interest will always be the bank's first priority & 4.52 \\
\cline { 2 - 3 } & My mistakes will be taken care of empathetically & 3.44 \\
\hline & $\begin{array}{l}\text { The bank will notify me of any issue that has relation with } \\
\text { my account instantly }\end{array}$ & 3.40 \\
\hline
\end{tabular}

\subsubsection{Facilitating conditions}

Our analysis shows the complex variable "facilitating condition" has a mean score of 2.486, meaning that respondents perceive facilitating conditions are favorable for them to opt for online banking. Under this complex variable, six variables were considered. Among these simple variables, "My family members and peers (friends and colleagues) who use online banking are satisfied with the services" had the lowest mean score (1.95). This indicates that respondents agree that they are more prone to using online banking as people around them are satisfied with their services. They also agree that as their closed ones who use online banking encourage them to use the channel that

Table 6: Perception of facilitating conditions

\begin{tabular}{|l|l|c|}
\hline $\begin{array}{c}\text { Complex } \\
\text { Variable }\end{array}$ & \multicolumn{1}{|c|}{ Simple Variables } & $\begin{array}{c}\text { Mean } \\
\text { Value }\end{array}$ \\
\hline \multirow{4}{*}{$\begin{array}{c}\text { Facilitating } \\
\text { Conditions } \\
(\mathbf{2 . 4 8 6 )}\end{array}$} & I have technical knowledge required to use online banking & 3.19 \\
\cline { 2 - 3 } & My peers (friends and colleagues) use online banking & 2.65 \\
\cline { 2 - 3 } & My family members and peers (friends and colleagues) who use online banking & 1.96 \\
\cline { 2 - 3 } & are satisfied with the services & 2.26 \\
\cline { 2 - 3 } & I have every equipment or infrastructure required for online banking & 2.47 \\
\cline { 2 - 3 } & I have people around me who can help me (if required) doing online banking & 2.39 \\
\hline
\end{tabular}

influences them to opt for online services. The respondents agree that they have people around them who can assist them in using the services which influence them towards online banking. However, the respondents were confused about their capability to use the technologies. As a whole, the facilitating conditions were found to influence customers toward online banking rather than inhibiting them to adopt the services.

\subsection{Intention to adopt online banking services}

Our analysis shows that the mean score of overall satisfaction with offline banking is 2.68 which refers that the respondents have a neutral perception (neither satisfied nor dissatisfied) about the services they receive from traditional banking. However, $64 \%$ of the customers were found to have the interest to switch to online banking if their concerns are addressed while about only $21 \%$ were interested to recommend others to use online banking if the concerns are addressed.

\section{Discussion and Recommendations}

Our analysis identifies the inhibitors that avert consumers to switch from traditional banking to online mode of transaction and also shows the factors of online banking that they positively perceive.

We found lack of trust and confidence in online banking system as the strongest inhibitor for customers to switch to online banking. Customers of traditional banking seem to have mistrust on the bank's customer services, complaint mechanism and risk management processes if those banking activities are conducted online. Given the rising number of complaints and scandals on fraudulent activities and embezzlements associating even the renowned banks in Bangladesh during the last few years, this fear of banking services conducted online might be rational for customers. Eventually, it creates resistance in customers' mind to switch to online banking.

Another inhibitor identified in our study is customers' perceived risk associated with online transactions. Customers who use traditional forms of banking have a doubt on privacy concerns, ease of irreversibility of mistakes made and loss of money in online transactions. This may be attributed to the fact that the spatial separation between customers and bankers in online banking creates a lot of vagueness and doubt about the system among the customers who are habituated with face-to-face contact in traditional banking. Although banks are continuously integrating user friendly features to reduce these uncertainties, the users initially will always feel the fear before changing their banking behavior.

While perceived trust/confidence and perceived risk are found as two key inhibitors, one of the motivators found is customers' perceived usefulness of online banking services. This claim is substantiated by the respondents' 
top reasons for choosing online banking. They strongly believe in the fast transaction time and easy accessibility of online banking services. This may be because when they go to traditional banks, many of them have to wait in long queues to deposit or cash in their money. Besides, the growing old age population cannot physically go to banks to complete their transactions and have to rely on others with their money matters. Online banking service works wonders in both these cases by bringing instant services in finger tips. Hence, we can argue that reducing lead time on banking transactions and making services available from everywhere can greatly influence customers' choice of mode of banking.

Another factor found to influence customers positively towards online banking is facilitating conditions. Though the customers of offline banking are not quite confident about the skills of their technical knowledge required for online banking, they are found to have people around them who could help them to use the system. Influence of peers and family members have been found to affect their preference of banking options. People are more inclined to listen to reviews from their family members who use online banking than anyone else. This belief may stem from proximity and trust on the influencers. New users or people who are thinking of switching to online banking may think that family members are more relatable, reliable and available to provide assistance if they face difficulties.

Although perceived usefulness and facilitating conditions of online banking are found to have positive influence on customers towards online banking, they are not so sure about how easily they can access this service. The lack of awareness about online processes and fear of facing technical issues are the main reasons behind this belief. Indeed, this uncertainty may stem from the fact that they have not yet availed the online services and are prone to the fear of changing transaction behavior. Also, the interface and processes of many online banking are not always suitable for all demographics, especially those who are not so adept in the latest technologies.

Our study also found that customers of offline banking are neither satisfied nor dissatisfied with the system they are using. Rather, the majority of them $(71 \%)$ were found to be willing to switch to online banking mode if their concerns (i.e., inhibitors) are addressed.

Based on our findings, we offer the following recommendations for the marketers and policymakers.

- The first and foremost concern for the banks and other relevant authorities should be taking necessary measures that would build trust/confidence in the customers' mind of offline banking services. Existing customers' complaints should be addressed promptly and empathetically. Any sort of technical issue arises or any mistakes done by a customer should be resolved in such a way so that the customer affected becomes satisfied and promotes the online banking services. Banks should highlight their activities they undertake to provide outstanding customer experience to the customers of online banking. This might help build customers' trust/confidence about their online services and would encourage offline customers towards online banking services.

- The Banking Act, ICT Act and MFS strategies should address the prevalent loopholes of online banking that allows perpetrators to engage in fraudulent activities. In addition, exemplary punishment to the frauds would prevent such fraudulent acts in the banks and customers' perceived risk on online banking might be reduced.

- Since people are confident about the usefulness of online banking, these benefits can be well assured by smooth service delivery to attract new customers and retain older ones. Focus should be given on reducing lead time on transactions and developing user interface to make it lucrative to even the most technophobic person. Banks should position their online services as a one-stop-solution to all the customer needs starting from digital KYC to international transactions.

- In order to make online banking more accessible and to attract customers who do not have adequate access to smartphones or internet, belonging to lower income range and old age groups, feature phone options can be introduced and well-marketed to these groups.

- Since traditional customers may face a myriad of technical issues while transacting online and much of their behavioral preference relies on the quality of customer services, banks should establish excellent customer care centers and train up customer service executives to aptly understand queries and patiently resolve the issues. AI can be integrated in query systems to identify unique problems and reduce backlog.

- National level awareness programs should be formulated to ensure the unbanked population can access mobile and online banking services that are available on minimum transaction costs. They should also be made aware of the benefits of saving money through different banks.

- Continuous targeted promotional campaigns to the traditional customers would make them informed of the features banks are introducing for them and might encourage them to switch to the online banking system altering their negative perception on few factors.

\section{Conclusion}

Collecting data from customers of offline banking, this study shows that perceived trust/ confidence and perceived risk are the key inhibitors for them to switch to online banking. It also shows that the traditional customers perceive 
online banking is useful and has favorable facilitating conditions. This study offers recommendations for practitioners and policy makers so that the concerns of the large majority of the traditional customers who intend to switch to the online banking are addressed and made them adopt the system. Since the study is limited to Dhaka city, further study could investigate the applicability of the findings in other cities. In addition, generalizability of the findings in developed countries could also be studied in future studies.

\section{References}

Almsalam, S. (2014). The Effects of Customer Expectation and Perceived Service Quality on Customer Satisfaction. International Journal of Business and Management Invention, 79-84.

Asli Demirguc-Kunt, L. K. (2017). The Global Findex Database. Washington: World Bank Group.

Barry Howcroft, R. H. (2002). Consumer Attitude and Usage and adoption of home-based banking in the United Kingdom. International Journal of Bank Marketing, 111-121.

Curran, J.M. \& Meuter, M.L. (2007). Encouraging Existing Customers to Switch to Self-Service Technologies: Put a Little Fun in their Lives, Journal of Marketing Theory and Practice, 15:4, 283-298, DOI: 10.2753/MTP1069-6679150401

Estrella-Ramon, A., \& Sanchez-Perez, M. \&. (2016). How Customers' Offline Experience Affects The Adoption of the Online Banking. INTERNET RESEARCH, 1072-1092.

Forrester Research. (2005, August 2). The State of Consumer Technology Adoption. Retrieved from Forrester Research: https:/go.forrester.com/press-newsroom/forrester-research-the-state-of-consumer-technologyadoption/

Ganguli, S. \& Roy, S. K. (2011). Generic technology-based service quality dimensions in banking Impact on customer satisfaction and loyalty. International Journal of Bank Marketing, Vol. 29 (2), 168-189. DOI $10.1108 / 02652321111107648$

Grabner-Kraeuter, S. (2002). The role of consumers' trust in online-shopping. Journal of Business Ethics, 39(Nos $1-2), 43-50$

Hanafizadeh, P., Keating, B. W., \& Khedmatgozar, H. R. (2014). A systematic review of Internet banking adoption. Telematics and Informatics, 31(3), 492-510.

Hoehle, H., Scomavacca, E., \& Huff, S. (2012). Three decades of research on consumer adoption and utilization of electronic banking. Decision Support System, 54(1), 122-132.

Hoffman, D. L., Novak, T. P., \& Peralta, M. A. (1999). Information privacy in the marketspace: Information Society, 15(2), 129-39.

Kelly, P., Lawlor, J. \& Mulvey, M. (2017). Customer Roles in Self-Service Technology Encounters in a Tourism Context. Journal of Travel \& Tourism Marketing, 34(2), 222-238. https://doi.org/10.1080/10548408.2016.1156612

Mamun, M. Z. \& Khan, R. H. (2014). Customers' Satisfaction of Islamic Banking and Conventional Banking in Bangladesh: A Comparative Study. Journal of Business Studies, Vol. XXXV, No. 1, April 2014.

McGrath, C. \& Astell, A. (2017). The benefits and barriers to technology acquisition: Understanding the decisionmaking processes of older adults with age-related vision loss (ARVL), British Journal of Occupational Therapy, 80(2), 123-131.

Meuter, J. M. (2007). Encouraging Existing Customers to Switch to Self-Service Technologies: Put a Little Fun in Their lives. Taylor and Francis, 283-298.

Mohamed A. Youssef, E. M. (2017). Modelling customer's intention to use e-banking in Saudi Arabia: an empirical study. International Journal on Business Innovation and Research, 239-260.

Iqbal, M. S., Hassan, M. U. \& Habibah, U. (2018). Impact of self-service technology (SST) service quality on customer loyalty and behavioral intention: The mediating role of customer satisfaction, Cogent Business \& Management, 5:1, 1 .

Murakami-Fester, A. (2020). What Are Online Banks? Learn the Pros and Cons. Retrieved from https://www.nerdwallet.com/blog/banking/pros-cons-online-only-banking/, retrieved on June 22, 2020.

Pietro, E. P. (2012). Understanding Consumer's Acceptance of Technology-Based Innovations in Retailing. Journal of Technology Management and Innovation, 70-79.

Reichheld, F. F., \& Schefter, P. (2000). E-loyalty: your secret weapon on the web. Harvard Business Review, 78(4), 105-13.

Salesforce Research. (2020). Customer Expectations Hit All-Time Highs. Retrieved from Salesforce Research: https://www.salesforce.com/research/customer-expectations/

Sharma, J. C. (2017). A Comparative Study on Motives of Online and Offline Banking Consumers: A Case Study of Udaipur City. Journal of Emerging Technologies and Innovative Research, 208-212.

Yang, J. and Klassen, K. J. (2008). How financial markets reflect the benefits of self-service technologies Journal of Enterprise Information Management, Vol. 21(5), pp. 448-467. DOI 10.1108/17410390810904238

Yi-Chun, H. J.-H. (2010). Gender differences in adolescents' online shopping motivations. African Journal of 
Business Management, 849-857.

Yoon, S. J. (2002). The antecedents and consequences of trust in online-purchase decisions. Journal of Interactive Marketing, 16(2), 47-63.

Dr. Rezwanul Huque Khan is currently serving as an Associate Professor at the Institute of Business Administration (IBA), University of Dhaka (DU), Bangladesh. He is involved with different ICT projects initiated by the government aiming Digital Bangladesh. Dr. Rezwan is a Commonwealth Scholar and pursued his $\mathrm{PhD}$ from University of Warwick, UK. He has been in academia for more than fifteen years and actively involved in research. His research interests relate to the transformative potential of digital technology as it pervades modern business and entrepreneurship. Dr. Rezwan's research focuses on digital innovation, entrepreneurship, consumer behavior in different digital platforms (e-banking, e-commerce etc.) and BoP markets. His recent articles have been published in the leading local journals and international outlets such Journal of Business Administration, Journal of Business Studies, Teachers' World, European Journal of Business and Research, and International Journal of Managerial Studies and Research.

Anika Shahjabin is currently working as a Business Development manager at Mayalogy Limited (Maya). She is leading the BGMEA-Maya services that ensures garment workers' access to affordable digital healthcare services and hygiene products. Previously she had worked for BRAC for 1.5 years as deputy manager of Leadership Academy. She completed her bachelor in Business Administration from Institute of Dhaka, with a major in Finance. Having made her foray in research during her undergraduate studies, her interest lies in digital innovation, social enterprise model and global and regional value chains. 